\title{
Virtual Family Play Therapy: A Clinician's Guide to using Directed Family Play Therapy in Telemental Health
}

\author{
Tiffany Smith $^{1}$ (1) Aaron M. Norton ${ }^{1} \cdot$ Latrisha Marroquin $^{1}$
}

Accepted: 4 October 2021 / Published online: 15 October 2021

(c) The Author(s), under exclusive licence to Springer Science+Business Media, LLC, part of Springer Nature 2021

\begin{abstract}
The field of marriage and family therapy was founded by innovators and pioneers, taking the practice of individual psychotherapy and making it systemic. Due to the impact of COVID-19, we now need further advancement by systemic therapists for telemental health services. The purpose of this paper is to propose recommendations and guidelines for adapting directed family play therapy from the same physical location services to telemental health. The article discusses recommendations for assessment, therapy structure, therapist roles, session preparation, and how to use virtual tools to enhance treatment. Systemic play therapy in a virtual format can work well if therapists make appropriate adjustments and rely on their creativity, high regard for ethics, and innovation.
\end{abstract}

Keywords Directed family play therapy $\cdot$ Telemental health $\cdot$ Virtual family play therapy $\cdot$ Telemental health training

The practice of therapy has undergone a revolution due to the impact of COVID-19, with therapists across the country shifting to conducting sessions virtually. However, most therapists had little to no experience conducting telemental health (TMH), and very few MFT training programs provided opportunities for experience training (Cravens et al., 2020). Until the pandemic, the literature on systemic practice in TMH was scant (Caldwell et al., 2017), compounding the challenges marriage and family therapists faced in moving their practice online in a safe, ethical, legal, and effective way. The impact of COVID-19 created a sense of hyperawareness that caused an immediate necessity for filling in the gaps in systemic TMH research. Journals across the globe are beginning to answer the call of therapists thirsting for TMH applications for working with families.

The field of marriage and family therapy was founded by innovators and pioneers, taking individual psychotherapy and making it systemic. We now need a similar revolution by systemic therapists in the field of telemental health. Although the pandemic has forced many therapists and clients to practice it out of necessity, TMH is not a new concept

Tiffany Smith

tntimmons@twu.edu

1 Department of Human Development, Family Studies, and Counseling, Texas Woman's University, Denton, TX, USA for the field of psychotherapy. Telemedicine has been practiced in the medical field for over a hundred years (Strehle \& Shabde, 2006). It has been slowly gaining traction for mental health professionals over the past two decades. However, our field has lagged behind others. While some researchers are doing great work in this area (e.g., Richard Bischoff, Jaclyn Cravens, Katherine Hertlein, Paul Springer), most research, training, and practice have been conducted by psychologists and counselors for individual therapy. Just as our founders changed the landscape of mental health through their innovation and creativity, the time is ripe for marriage and family therapists to bring this same spirit of innovation to the practice of TMH.

In this spirit, the purpose of this paper is to propose recommendations and guidance for how to adapt directive family play therapy to TMH. We believe that directive family play therapy (DFPT) is an excellent approach to relational telemental health because of its ease of use and direct approach. However, it is also one that has inherent challenges to adapt. While most clinical models can be easily adapted using a telemental health platform (Grady et al., 2011), those that require interaction between the therapist and clients, such as play therapy, can be much more challenging to adapt. No published refereed scholarship currently recommends or proposes methods and interventions for adapting systemic family play therapy to TMH. We believe that therapists can 
adapt directed family play therapy to be just as effective through virtual services as it is through in-person services.

Before researchers can test new methods, those methods must first be developed and proposed. We aim to be among those who take this first step and propose those methods in this paper. The methods, interventions, and recommendations suggested herein come not only from our own experience as systemic TMH practitioners but also from the wider field of systemic TMH therapists. We thank all those who consulted with us throughout the years, sharing their knowledge, experience, and ideas. One of this manuscript's primary purposes is to give systemic therapists a starting place to begin adapting TMH to play therapy, open a greater dialogue in the scholarship for methods and techniques to conducting systemic $\mathrm{TMH}$, and give researchers a base to do systemic TMH research. We see this paper as a first step into systemic play therapy in TMH. We invite other family therapy scholars to add to the literature and give a greater collective knowledge base to explore this new medium for delivering systemic services to families and children.

\section{Directed Versus Non-Directed Family Play Therapy}

Children may have difficulty expressing feelings verbally in family psychotherapy due to a lack of comprehension of emotions, emotional conflict, or emotional avoidance (Fromberg \& Bergen, 1988; Harter, 1977). In addition, many models of family psychotherapy are not designed for active young children (Botkin, 2000). Thus, integrating play into family psychotherapy becomes a powerful approach allowing children and adults to build and heal relationships (Botkin, 2000; Drewes et al., 2011).

Play therapy allows children to project feelings through a medium of specially selected symbolic play toys (Landreth, 2012). Play for children is a natural language of symbolic representation in that it allows children to work out experiences that have been perplexing or distressing (Landreth, 2012). Symbolic play for children "bridges the gap between concrete experience and abstract thought" (Landreth, 2012, p. 16; Piaget, 1962). Through play, children's emotional expression allows for deep meanings within their subconscious to be expressed without attempting to please the adults in their adult language (Axline, 1950; Landreth, 2012; Piaget, 1962). In Non-directed play therapy, the therapist's role is to create a safe environment for self-expression, accept the child fully where they are, and allow the child to lead the sessions (VanFleet et al., 2010). The child obtains insight from the therapist's tracking and reflection interventions. The "child leads and the therapist follows" (VanFleet et al., 2010, p. 21).
In Directed Family Play Therapy, treatment focuses on directing the family to change through play (Ariel, 1992). The therapist directs the play communication through treatment planning and developmentally appropriate play directives that address family functioning and problems. This approach varies significantly from non-directive play therapy theory, where the focus is the child leading the sessions (Landreth, 2012). Rather than simply relying on the parent perspective alone, DFPT allows the therapist to observe the parent-child relationship's communication and interactions. Additionally, it allows parents and children to practice communication and coping skills during treatment, which results in better outcomes than parent-training programs alone (Kaminski \& Claussen, 2017; Kaminski et al., 2008). The goal of DFPT is to create a safe environment whereby therapists can develop play therapy scenarios within the child's zone of proximal development that challenges both the parents and the child's unconscious process and defense mechanisms (Rasmussen \& Cunningham, 1995). This then leads to triggering the family roles and interaction patterns to manifest in session. Fleming and colleagues found that parents who provided negative attention during child-directed play interventions had children with higher conduct problems at home and school during middle childhood. Therapists can utilize the DFPT model to assist children whose parents report behavioral problems at home and school (Fleming et al., 2017).

This model posits that the presenting problem is a symptom of the family system (Ariel, 1996; Eaker, 1986). Therefore, an additional component of DFPT is that when therapists work with the entire family, the therapist must align with each family member to understand the problem better and become part of the system (Haley \& Richeport-Haley, 2003). Therapeutic alliance and joining build trust among the family members and is crucial for systemic change. When working with young children using DFPT, therapists join and express understanding of the family system through play.

The DFPT therapist creates, directs, and is active throughout family play sessions. The therapist will stage "possible worlds" of imaginative play to allow the parents and child to communicate their perceived and ideal realities (Ariel, 1992, p. 19). The therapist continually observes all family members' behaviors and communication to determine the next steps to take (Ariel, 1992). Family play is a source of gathering information about the family's communication and relationships, followed by the use of play as an instrument for facilitating change (Ariel, 1996). The directive play method focuses on using parent-child relationship training and skill-building using a prescriptive approach to playbased interventions (Drewes et al., 2011). For children who do not yet have the cognitive skills necessary to implement coping behaviors, the therapist coaches them to develop and 
practice new problem-solving skills within the playroom (O'Connor, 2001). When using DFPT, the therapist coaches the parents and the child(ren) to develop these skills within the playroom. Because of the model's flexible and directive nature, DFPT can easily be adapted to an online platform.

\section{Benefits of Telemental Health \& Family Therapy}

There are many benefits for therapists to utilize TMH for DFPT (see Table 1). While the purpose of this article is not to provide an exhaustive review of the benefits of TMH, we review the most important benefits here. First, TMH provides a unique opportunity for therapists to gather information by viewing families in their homes, similar to homebased family counseling (Tate et al., 2014). Therapists can witness the family communication and interaction within their home environment as one child jumps on the couch, one child colors silently on the floor, and the reactions of the parents and the family dog.

Second, TMH can potentially reduce barriers to systemic treatment. With greater accessibility and ease of use, families have more immediate access to telemental health services (Campos, 2009). Underserved populations and those living in rural areas can utilize telemental health services and reach a broader range of therapists who may specialize in their needs (Nelson \& Patton, 2016). Because of technology's continued advancement, younger populations are more open and comfortable using TMH for treatment (Boydell et al., 2014). Families studied using video platform sessions reported feeling comfortable and safe in their own home, less stigmatized about receiving treatment, and that treatment is more convenient (Lingley-Pottie \& McGrath, 2008). Families report increased satisfaction with telemental health due to the convenience of meeting in their own homes (Wade et al., 2004).
Third, families' treatment goals can be achieved using telemental health platforms (Nelson \& Patton, 2016). Efficacy is not lost through telemental health sessions versus face-toface sessions (Perle \& Nierenberg, 2013). One concern for therapists has been a fear of loss of the therapeutic relationship through a video platform. However, parents and children report a strong therapeutic alliance with the therapist using telemental health (Wade et al., 2004). Results from online family psychotherapy with children who had experienced traumatic brain injury revealed similar results to those previously conducted in face-to-face sessions (Wade et al., 2004). Child psychiatrists can provide an accurate diagnosis, and families report high satisfaction using telepsychiatry (Boydell et al., 2014). The use of Cognitive Behavioral Therapy (CBT) interventions using telemental health is as effective as face-to-face sessions with children and adolescents (Boydell et al., 2014). A study investigating TMH versus face-to-face treatment of 233 children with Attention Deficit Hyperactivity Disorder found that children in both groups demonstrated improvement with treatment. Additionally, the caregivers reported that children with ADHD significantly reduced behavioral problems at home with TMH treatment (Myers et al., 2015).

Fourth, TMH makes it easier to have all family members present for family sessions, especially working parents. Due to scheduling conflicts and transportation issues, getting all available caregivers and siblings to a family can often be challenging. It is not uncommon when parents request therapy that one child is the identified patient, and typically one parent brings the child to sessions. Using an online platform allows for reduced scheduling conflicts. It can thereby increase all family members' attendance because the therapist can schedule appointments when all caregivers and family members are home to attend sessions.

Table 1 Summary chart of benefits, challenges, and contraindication of directive family play teletherapy

\begin{tabular}{|c|c|c|}
\hline Benefits & Challenges & Contraindications \\
\hline $\begin{array}{l}\text { Reduce systemic barriers to healthcare acces- } \\
\text { sibility }\end{array}$ & $\begin{array}{l}\text { Therapist cannot physically interact with } \\
\text { family }\end{array}$ & $\begin{array}{l}\text { Previous trauma or abuse in the home environ- } \\
\text { ment }\end{array}$ \\
\hline $\begin{array}{l}\text { Initial research demonstrates TMH is effica- } \\
\text { cious treatment modality }\end{array}$ & $\begin{array}{l}\text { No existing research on TMH family play } \\
\text { therapy }\end{array}$ & $\begin{array}{l}\text { Parents unable or unwilling to communicate } \\
\text { through play }\end{array}$ \\
\hline View family in their home environment & Creating safe environment in family's location & $\begin{array}{l}\text { Therapist determines that face to face treatment } \\
\text { is necessary to model play therapy commu- } \\
\text { nication }\end{array}$ \\
\hline $\begin{array}{l}\text { Convenient for families and may permit more } \\
\text { members to attend }\end{array}$ & $\begin{array}{l}\text { Advanced session planning and communica- } \\
\text { tion with clients }\end{array}$ & Any TMH contraindications \\
\hline $\begin{array}{l}\text { Requires parents to be highly involved in } \\
\text { sessions }\end{array}$ & Hardware and software needs & Any play therapy contraindications \\
\hline
\end{tabular}




\section{Adapting Directed Family Play Therapy to TMH}

Whether using DFPT in the exact physical location or virtual services, the theory of change works the same. The family meets together all in one room and interacts in much the same way for both delivery methods. The family engages in directed play activities developed and planned by the therapist, and the focus of treatment is on the treatment goals, which are developed collaboratively with family members. This collaborative effort establishes rapport with the family and reframes the problems as a family issue, rather than one person being viewed as the problem. The therapeutic alliance with parents is essential to the parent coaching portion of DFPT by ensuring parents follow the therapist's directive play during family play sessions. However, in virtual telehealth sessions, the therapist is not physically present with the family in their home environment.

In this section, we propose our recommendations for adapting family play therapy to TMH services. This paper is not intended to serve as a general overview of the practices or ethics of TMH generally. The following recommendations assume that therapists have adequate training and knowledge in $\mathrm{TMH}$. These guidelines predicate therapists who practice ethically and legally and fundamentally work on the logistic and clinical adaptations necessary to provide telemental health services. Consequently, these recommendations focus solely on those related to the adaptation of systemic play therapy.

\section{The First Session}

Typically, a family play therapist would have the whole family present at the first session for initial assessment and then follow up with a parent consultation. In face-to-face sessions, the family comes into the therapist's space, wherein the therapist has various specific play materials to use in each session. However, in TMH, the therapist cannot do this without advanced planning with the parents. Consequently, the first adaptation that therapists need to make is planning and preparing for the first session. We suggest that this begins by flipping the first session's structure by holding a parent consultation before the first family session.

\section{Needs Assessment}

Before the first family session, it is necessary to conduct a needs assessment during the initial parental consultation. DFPT is most effective with families with children under the age of 8; however, it has also been beneficial for some children up to age 11 (Lin \& Bratton, 2015). Obtaining information on the child's play and assessing for safety concerns is essential to determine appropriateness for DFPT. Providing psychoeducation to parents on DFPT and what to expect in session is necessary for the needs assessment. Explaining to parents that the children may not view the problem in the same manner as adult family members. For example, explaining to parents, "Sally may not feel comfortable talking about her lying or even understand it. When we play, some toys may start lying. This is her way of working out through play what she cannot express verbally because she lacks understanding."

Additionally, in DFPT, children are not actively engaged in talk therapy; instead, they communicate through play. Therefore, the family will use the child's play language to communicate with the direction and help of the therapist. Defining therapeutic boundaries, healthy feeling expression expectations, limit setting, and therapeutic goals are also essential to address in the needs assessment.

Therapists need to evaluate the family's play, art, and technological resources during the needs assessment to determine how to structure and prepare for TMH sessions. Additionally, since the family play sessions are taking place in their home, obtaining information from the parents on their comfort level using messy play items such as playdough, glue, paint, and markers is essential. During this needs assessment, it is also vital to obtain information from the parents regarding any family rules restricting specific toys, magic, or games in their home.

When conducting telemental health services, therapists need to communicate in advance with families to have the necessary play materials ready. This allows the therapist to plan session activities intentionally and know what kinds of activities are even possible. In the initial consultation, therapists should obtain a list of play items the parents have in the home and, if necessary, additional items that would be important for the parents to obtain. Therapists might need to direct parents to acquire necessary items before a session. For example, if puppets are needed for a role play for the next session, therapists will direct parents to make a certain number of puppets using paper plates, paper sacks, socks, or other household items. For families that do not have the needs or ability (e.g., low SES or high-stress families) to make or purchase items, it may also be necessary for the therapist to mail items to the family in advance. Without a needs assessment, the therapist would not be able to plan for sessions or assure that the family will be prepared for the session's planned activities.

Conducting a needs assessment can be made easier with documentation and premade handouts. Because families may have widely different resources, the therapist must accurately and carefully document the needs assessment results. Premade handouts can make this even easier. A simple checklist of items, organized by type of resource (art supplies, dolls, animal toys, printer, paper, etc.), can significantly benefit the 
therapist in documenting the family's resources and planning according to each family's resources.

\section{Family Play Therapy Toolbox}

After conducting a needs assessment, the therapist can then work with the family to develop an individualized family play therapy toolbox, a designated box of supplies for family play therapy sessions. The family needs to have play therapy resources for virtual sessions similar to those that the therapist has in their office. The therapist and family need to have a similar set of toys for imaginative play for story congruence, structure, and organization (Dimitropoulos et al., 2017). Having a family play therapy toolbox would allow for ease of access for families during sessions, create consistency for the children, and allow easier planning for the therapist. Rather than calling the family before each session to have the family gather play resources for the session, the family can have one box of resources to be used from session to session.

When deciding on the family toolbox materials, it is essential to remember that each item has a purpose in helping the family reach their therapeutic goals. In-play therapy, "toys are viewed as the child's words and play as the child's language - a language of activity which may contain more meaningful material than verbalized words" (Landreth, 2002, p. 529). Helping families understand the importance of play and items in the toolbox is a meaningful conversation to have with parents to prepare a meaningful toolbox for therapy.

Using the objects in the toolbox creates opportunities for families to learn, practice, and demonstrate skills during telehealth sessions. Suggested items for the family play therapy toolbox include a variety of miniature, real-life figurines of humans and animals, baby dolls, small vehicles (e.g., Hot Wheels), soft or squishy balls, games, and creative/expressive art materials. According to Landreth (2002), specific items such as handcuffs with a spring-release, two colors of soldiers, a 4-ft. rope, and a toy gun help children express anger, frustration, or hostility. Toy animals (predators and prey) and farm animals, cats, dogs, spiders, and snakes can be used to act out experiences or scenarios directed by the therapist. For example, the therapist can present a situation in which Milly the Goat ate Farmer Joe's tractor tire, and now Farmer Joe cannot plow the field, or Fido, the family cat, feels sad since little David received a puppy for his birthday. Puppets help children communicate their emotions, recreate life events, and test new behaviors (Desmond et al., 2015). According to Bromfield (1994), puppets are the most helpful tool for children and families because they are fun and can be made from everyday household items. Puppets can be made with old socks, paper plates, or paper sacks. Legos are another must-have in the toolbox. There are many ways to use Legos that require the family to have mutual goals, effective communication, and shared attention. For example, family members have to complete the task of creating a Lego structure and are given roles, including a planner who reads the Lego set's instructions, a searcher who finds the pieces, and the builder who constructs (Peckett et al., 2016).

Art provides a way for family members to convey thoughts and feelings while being creative, so the following list of items are essential to have in the toolbox: paper, a pencil, Crayons (8-count to avoid too many choices), paint, blunt scissors, non-toxic glue, and Play-doh (Landreth, 2002). Other imaginative supplies such as pipe cleaners, popsicle sticks, colored paper, notebook paper, and transparent tape can also be added to the toolbox (Landreth, 2002). Paper plates are also an excellent substitute for eraser boards. Clients can draw their feelings on a paper plate and hold it up as a mask to communicate with family members or write on the plate; however, they might opt for using a small dry erase board during games. Families can also take advantage of their natural surroundings by adding sticks, rocks, and leaves to their toolbox. Children can use their imagination with rocks and often give them healing or magical powers (Linn, 2010). Soft, squishy balls can help children remember whose turn it is to speak by tossing the ball to the family member who "has the floor." Playing cards have many uses and can be a great addition to the toolbox. For example, families can be instructed to play Go Fish. If a heart is drawn, they share a feeling they are experiencing; if a spade, the player talks about their favorite family memory. If a diamond, they say something nice about the person sitting to their left. If a club, they name something for which they are thankful. Therapists and families should also consider adding a kitchen timer to the toolbox for timed activities and boundary setting.

Therapists and families need to discuss appropriate and available toys to choose the best toys for each family's toolbox that align with their specific therapy goals. Many of the materials discussed can be found in the home or purchased at a local thrift or discount store. Families should be instructed to keep the therapy toolbox supplied with materials and toys that will only be used during therapy sessions and stored safely between sessions unless otherwise instructed. Continued parent consultations between sessions can be conducted to evaluate and reevaluate the family play therapy toolbox. It may be necessary to restock certain supplies, remove others, or add new items as therapy progresses. Additionally, therapists must assess for appropriateness of the family's multicultural values and beliefs to determine if specific toys or games would go against their values. 


\section{Technology}

One key difference between individual TMH and systemic TMH is multiple clients' presence in a single video conference call. Moreover, for family therapy, it is recommended that family members treat telemental health sessions similar to face-to-face sessions as much as possible (Wrape \& McGuinn, 2019). Therefore, it is ideal for the family members to be together in one location, rather than on separate video screens as can be done in other systemic therapies (e.g., couple therapy). This is so the therapist can monitor the play interaction of family members in a single location that mimics their real-life interactions. However, this presents unique challenges for the therapist to direct, view, and hear what is occurring on the family's side of the video conference. Consequently, there are several unique adaptations and requirements for equipment, placement, lighting, and sound when conducting DFPT in a single location.

\section{Camera Equipment and Placement}

Setting up an environment where all family members can be seen on camera is essential to systemic TMH (Nelson \& Patton, 2016). When utilizing the family's home rather than a video therapy site, clear communication from the therapist on the best place to set up the virtual session should be communicated, tested, and continually reassessed. It may even be necessary to move and change the camera placement during the session as family members move and play with each other. The therapist needs to see the family's play and interactions, sometimes at different angles or levels (Dimitropoulos et al., 2017). One way to minimize the need to move the camera too often is to use a table with play items or a designated area rug that could help focus the family on playing in a specific area and direction. The therapist can then work with the parents to find a camera placement to best capture this area so that the therapist can easily see the interaction. Doing so can prevent having to spend too much therapy time finding adequate camera placement.

Whereas TMH can often be done on a tablet or phone, having a laptop or desktop allows for better equipment suited to systemic TMH. For example, external cameras are often much better compared to internal cameras and microphones as they allow for greater movement, wider viewing angles, and often have much better microphones. That way, the family can keep the therapist stationary while placing the camera in a higher or better location. Laptops and desktops likewise have larger screens or the ability to connect to a larger screen than tablets and phones. A larger screen would make it easier for all family members to view the therapist despite where they are located in the room. However, suppose it is determined that the family only has a small screen such as a tablet or phone during the needs assessment. In that case, the therapist should adapt play therapy interventions and utilize innovative ways to best capture the family play sessions. For example, placing a phone on top of a tripod or a tall object to view the play space better is an innovative way to work with the family's technological resources.

\section{Lighting and Sound}

Proper lighting is essential to be able to view the family adequately in the whole play area. When setting up the play space for the session, it is essential to test out the area to examine where overexposure (too much backlight) or underexposure (too much darkness) may hinder the therapist's ability to observe the family. We recommend this be included in the needs assessment and initial consultation so that the play area can be set up with adequate lighting for the session. It may be necessary for the parents to move lights, cover lights, or adjust window blinds to create a lighting environment where the therapist can adequately view the whole play area.

Just as it is essential to see all family members, it is vital to hear all family members. When working with large families or active children, having external microphones can be extremely helpful. While many external cameras also have HD microphones that will be more than adequate, purchasing external microphones may be helpful or necessary. Microphones with long cords can be purchased for \$20USD, which allows for microphone movement during the session and greater flexibility for the therapist to hear the family members wherever they may be in the room.

\section{Technology Testing \& Instructional Materials}

During the initial consultation with the parents, and as necessary throughout treatment, it is crucial to communicate clearly and directly with the family how to use, set up, and troubleshoot technology. Creating instructional materials (e.g., videos and handouts) that walk clients through setting up their own space can help initial consultations move quickly and easily. Such instructional materials can also help clients understand the best camera placements, lighting, and which kinds of equipment are recommended. Consequently, we suggest that these materials be easily accessible to clients and provided before the initial parent consultation.

Therapists must be flexible and assertive about lighting, sound, and camera equipment for family therapy TMH sessions (Wrape \& McGuinn, 2019). Therefore, we recommend that the therapist and parents test and troubleshoot the play space setup and assess video, lighting, and sound equipment before the first family session during the initial parent consultation. This tech run-through can also allow the therapist and the parents to assess if additional equipment is needed for purchase. 
After conducting the needs assessment of play, art, and technology resources, therapists must consider whether it would be necessary to purchase or loan equipment for families who do not have the necessary financial means to obtain the appropriate equipment for TMH sessions. This can include play and art therapy kits, cameras, laptops, and microphones. When this is not possible or feasible, the therapist's flexibility and creativity become extremely important. For example, if the family has only one working tablet with poor mic quality, the therapist may adapt to where the tablet is placed where the family can be viewed with the mic muted, and a cell phone is used for audio. Again, therapists and families must be flexible and work together to determine the best technical and strategic approach.

\section{Therapist Role: Play Coach}

One of the critical adaptations necessary for DFPT in telemental health is that the therapist must take a directive role as a play coach. Because therapists are not physically present in the room to direct and participate in the play, therapists must direct parents to perform all of the play. While the therapist can play virtually, they cannot have the same shared play touch through the screen as they have in faceto-face sessions. Thus the DFPT must be evident in communication on directing the play, explicitly using a virtual platform. In a virtual session, therapists will need to direct the parents' movements using verbal communication. For example, "Mom, I want you to choose an animal out of the animal toys to show me what it feels like when you are feeling mad." The mother would choose an animal and play out the feelings, with further direction from the therapist as necessary. The therapist would then state to the child, "Now Johnny, now you pick an animal from the animal toys and show me what it feels like when Mom is feeling mad." The child would then select an animal toy and then play out his feelings towards the mother. Therapists in virtual sessions must be detailed in their verbal directives to parents communicating with their children through play.

\section{Setting Limits}

Using the language of play allows children to bring their emotions to the surface; no emotional expression is taboo, including feelings of aggression (Landreth, 2002). Additionally, children may not have an awareness of how their emotions are manifesting in session. Limit setting helps create awareness of responsibility, self-control, boundaries, and emotional safety by anchoring the session to reality (Landreth, 2002). Therefore, working with children during family therapy is vital to the therapeutic relationship for the therapist to set limits. These limits can range from how toys and others are treated, length of the session, voice volume, and participation during the session to create a safe place to express feelings. For example, in a face-to-face session, should a child leave the therapy room, the therapist may choose to redirect the child to the session's rules, and the parents would reinforce this limit bringing the child back to the session. However, during a virtual session, a child could feel freer to leave due to a session being held in the child's home, a place without the same kind of location and physical boundaries as a therapist's office. The essentials of limit setting can be used by therapists and modeled to parents for future use. The limit setting formula is: "Step 1: acknowledge the child's feelings, wishes, and wants; Step 2: communicate the limit; Step 3: target acceptable alternatives" (Landreth, 2002, p. 533). Therapists must communicate and continually reevaluate with parents how to troubleshoot limit setting during family therapy sessions.

Pre-session routines and environmental queues are two ways to help manage the additional challenge of therapy boundaries. One of the critical differences between in-person therapy and TMH is the minimal transition time required for TMH. For example, there is no drive to the therapist's office or waiting for your appointment in a waiting room. With some planning and preparation, therapists and parents can help give children a developmentally appropriate transition into the session. Because therapy is taking place in the child's home environment, we recommend that therapists work with families to establish routines and rituals before the session starts. For example, children should have had a drink, snack, and use the restroom. Depending on the child's age and maturity, parents can include children in preparing the therapy space for the session, including preparing lighting, getting the play therapy toolbox, spreading out a rug or blanket, or getting the laptop or tablet in place.

This preparation helps give the child time and space to emotionally and mentally prepare for the therapy session and establish environmental queues similar to those in a therapy office. Changing the space by making a family play therapy area creates an environmental queue that is now a unique and special time with different boundaries and rules than typically occurs in the home. We recommend that the therapist and parents reinforce these environmental queues directly (e.g., "We are now in special playtime. This time has different rules than you normally have in your house. These rules include..."). The therapist and parents can also use additional environmental queues, such as a visual timer demonstrating the time spent or remaining in the special family play session (Dimitropoulos et al., 2017). This can help children learn the boundaries of remaining in that room for family play sessions during that special time. Play therapists go to great lengths to make their office play space unique and safe, and we recommend doing the same for the home play space. Doing so requires the therapist to be directive and coach the parents through this process. The therapist cannot 
be physically present to establish rituals and environmental queues for the family.

\section{Transitioning out of Session}

Although transitioning out of the session using a virtual format may be quicker, the family needs to build transitional rituals. There is no walk-out of the office or car ride home. Building in some decompression or processing time can be just as crucial for children as it can be for adults, especially for emotionally intense sessions (Wrape $\&$ McGuinn, 2019). Following family therapy with a ritual of putting away the therapy materials with music or doing a lighthearted activity, game, yoga, or meditation exercise can allow families to shift out of the session into a different headspace before returning to the "normal" life at home.

\section{Preparing for Subsequent Sessions}

When conducting virtual sessions, treatment planning requires organization and weekly communication with parents. In the DFPT model using a virtual platform, the therapist is the play coach, and the parents perform the play with the child(ren). This approach requires communication and directives with parents before each session. Parents must be provided ample time to prepare for the session. Therefore, therapists must decide what day to communicate the treatment plan for the week for each family. This consistency allows parents to be prepared mentally and logistically to ensure they have all the necessary items before the session. For example, if worksheets need to be printed and cut, the parents need time to perform these tasks in advance. If specific items are needed that are not in the premade play therapy kit, parents need ample time to secure them for the family play session and put them in the play therapy kit.

This advanced preparation requires additional time for the therapist, and each therapist must find ways to block out time for treatment planning and communicate to parents. This process ensures both therapists and families have equal opportunities for family play therapy sessions to be organized and consistent. For example, the DFPT therapist would inform families that they will receive an email of the upcoming family play session and items required every Friday. Friday afternoon, the DFPT therapist would email the Hernandez family addressing their treatment plan, "This week we will be working on family communication. For our family play session, you will need two zip log bags filled with fifteen identical Legos in each bag. Label one bag A and one bag B." The Hernandez family would receive an email addressing their specific treatment plan stating, "This week, we are using finger puppets to work on family relationships. Please print out the attached puppet characters and cut them out for our session. Feel free to color them if you choose." While this may require extra time during the week, it is essential to create consistency for families to feel comfortable and prepared when they attend their virtual session. Additionally, it allows therapists not to spend session time with family members locating items that might not have been in their toolbox.

\section{Online School \& TMH}

Online schooling is becoming a choice some families have made for their child's education. Many children have experienced online schooling, especially throughout the COVID19 pandemic. We recommend therapists assess the family's experiences with online learning and how the children have responded. Careful assessment can help therapists avoid or mitigate negative experiences or experience challenges from countertransference of negative online learning experiences. TMH can quickly feel the same as online learning for children, impeding the therapy process due to countertransference. We recommend that therapists capitalize on what works well for the family and find ways to make therapy different from online school in the ways that matter most.

\section{Using TMH Platform to Enhance Change}

The virtual format of TMH affords unique tools and structural differences from face-to-face therapy that can potentially contribute positively to the change process. When therapists direct play in face-to-face sessions, the play takes place in a controlled office environment outside of the family's home environment. The parents and the child(ren) are provided verbal directives by the therapist to create change at home by recreating the therapeutic environment interactions at home. When families leave the controlled, therapeutic environment created by the therapist and return to their natural, home environment, their usual communication and interaction patterns can create barriers to change. Families who the therapist instructs to complete a homework assignment may feel uncomfortable or anxious about doing homework outside of the office and in their own home. The familiar, safe, and controlled office is where families are used to working together. The transitional phase from office to home is eliminated in a virtual setting because the therapeutic environment interactions are actually occurring within the home.

During systemic TMH, play interactions occur in a controlled environment within the family's home environment. Thus, the directed play can easily be repeated in the home because it has already occurred in the home. For example, a 
therapist interested in directing a family to talk openly about emotions and validate feelings may play the "Feeling Hide and Seek" card game during a session. In this card game, each family member would take turns hiding a card with a feeling written on it in the room for the other players to find. When the feeling card was found, the DFPT would ask them to recall a time when they each experienced that emotion. At the conclusion of the game, the DFPT would give the feeling cards to the family and direct the family to play this game again at home. Since the family has not played the game outside of the office, barriers could arise. The feeling cards might get lost or not even make it out of the car. During a virtual session, the family has already played it in the home. The cards are there, ready to use. The virtual session makes the transition from session to homework much easier for family members because it is more familiar.

\section{Using the Virtual Presence}

Therapists can also use their virtual presence in ways to enhance therapy gains and augment treatment. With appropriate technology and consent, therapists can record session segments, as they already have cameras and audio equipment well positioned on the family. These recordings can help the therapist review sessions and playback to the family for additional interventions. Therapists can also use the reduced power of the virtual presence to enhance treatment. Therapists can intentionally make their virtual presence smaller to give parents greater power and responsibility for their family's change process. By requiring parents to do more and be the physical presence with the child, therapists can take advantage of their reduced power to make the parents the agent of change in the family more quickly and effectively. For example, because the therapist is not physically present, he/she may be less inclined to "step in" during a moment of silence, uncertainty, or disagreement the family may be having. This can be helpful when the family tends to rely on their therapist to "help" or "rescue" them during a difficult time in the session. This reduces the presence and influence of the therapist and empowers the family to make adjustments to be their own agent of change.

\section{Technology Facilitated Play}

Another way to adapt DFPT to TMH is to integrate technology-assisted play resources, such as virtual whiteboards, sand trays, and games, into the therapy session. Many video conferencing platforms have whiteboard features that therapists and families can efficiently utilize during virtual sessions. Additionally, there are virtual sand tray programs, online board games, card games, trivia and quiz games, and virtual playroom programs. When utilizing technology-facilitated play, therapists must follow play therapy standards regarding the use of computer programs as beneficial for treatment (Luxton et al., 2016). Additionally, all HIPAA and HITECH guidelines must be followed as well.

However, there is one notable drawback of using such technology-assisted play resources. Many technologyfacilitated play programs are designed for interaction with one person on each screen and may not be ideal for family therapy. This can lead to family members crowding around a screen or taking turns on the device, thereby minimizing therapists' ability to view members' faces and body language. Additionally, this can lead to the family members interacting with the screen rather than directly with each other through play. Therefore, therapists should carefully consider the fit, purpose, benefit, and HIPAA compliance of any technology-assisted play resource before integrating it into play therapy sessions.

\section{Cautions and Contraindications}

As with any treatment modality, it is essential to consider contraindications to TMH treatment with families (see Table 1). First, therapists should assess whether the home is a safe environment to conduct TMH. This is especially important as safety is critical to successful and ethical play therapy practice. If there is any history of abuse or neglect in the home, children can feel unsafe or retraumatized by holding therapy in a place where abuse or neglect has occurred. Therefore, part of initial consultations needs to include a history of abuse and traumatic events of the space itself and, if necessary, move therapy to a different location. A thorough review of assessing for abuse in a TMH session is beyond the scope of this manuscript. For more information, we recommend the following resources:

- Technology safety (National Network to End Domestic Violence, 2021).

- Violence, abuse, and neglect in telehealth (New South Wales Government, 2021).

Second, therapists must follow any contraindications for $\mathrm{TMH}$, as contraindications for TMH generally would likewise apply to virtual play therapy. This requires therapists to assess the fit of TMH regularly, be trained in TMH practices, and have all the required hardware and software for TMH practice. A full review of TMH contraindications is beyond the scope of this paper, and we suggest readers review the following resources:

- Best practices in the online practice of couple therapy (Caldwell et al., 2017).

- Teletherapy guidelines (Association of Marital and Family Therapy Regulatory Boards, 2016). 
- A practitioner's guide to telemental health: how to conduct legal, ethical, and evidence-based teletherapy (Luxton et al., 2016).

Third, therapists must follow any contraindications for directive play therapy and in-home play therapy generally. For example, children who struggle with remaining in the designated virtual playroom, refuse to participate, or follow the therapist's directive may not be appropriate for play therapy. Likewise, parents who are either unwilling or unable to follow therapists' directives to engage in play would contraindicate play therapy treatment. Not all children and families are a good fit for directive play therapy, and a non-directive, childcentered approach may be a better fit. Consequently, therapists must plan for transitions to another treatment approach or provider should they determine a family is inappropriate for DFPT (for more, see Landreth, 2012; Ariel, 1992; Bailey, 2005).

\section{Call for Future Research}

The suggestions, recommendations, and guidelines proposed in this paper are based on the authors' anecdotal experiences, informal discussions with other TMH therapists, and the existing literature on TMH practice. Consequently, these recommendations need to be researched and tested. There is very little research on DFPT using a virtual platform. COVID-19 changed how therapists practice and how DFPT is being used. The pandemic forced therapists to begin practicing with only knowledge of their model and telemental health training. This lack of resources and research forced therapists across the globe to do the best job they could with what they knew. As technology advances and more therapists are comfortable using DFPT, it must be researched. Qualitative studies exploring the lived experiences of therapists, parents, and children participating in DFPT using a virtual platform are imperative for laying the groundwork for future research.

Additionally, the need for controlled studies, case studies, and focus groups of both therapists and families would help advance the field on implementing DFPT using a virtual platform. One of this paper's primary purposes is to propose methods, structure, and theory for conducting systemic TMH play therapy that researchers can test and evaluate. Future studies would allow proper training and implementation in the treatment of families using the DFPT model.

\section{Summary}

DFPT is a unique model that allows for a pragmatic approach to working with families with young children. In this paper, we have proposed various methods and recommendations for how therapists can adapt directive play therapy to the practice of TMH. Table 1 includes a summary of the benefits, challenges, and contraindications. We recommend that therapists begin with a parent consultation to conduct a needs assessment, test technology equipment, establish a special play therapy place, and create a play therapy toolbox. We also recommend that therapists take a more direct approach, as the parents must be the actors of change while the therapist has a virtual presence. This virtual presence requires additional session preparation time, advanced communication with parents before sessions, and augmenting how therapy limits and rules are set. Play therapy in a virtual format can work well if therapists make appropriate adjustments and rely on their creativity, high regard for ethics, and innovation in the spirit of our field's founders.

Funding The authors did not receive support from any organization for the submitted work.

\section{Declarations}

Conflict of interest The authors have no relevant financial or non-financial interests to disclose. The authors have no conflicts of interest to declare that are relevant to the content of this article.

\section{References}

Ariel, S. (1992). Strategic family play therapy. Wiley.

Ariel, S. (1996). Restorying family therapy. Contemporary Family Therapy, 18(1), 3-17. https://doi.org/10.1007/BF02196847

Association of Marriage and Family Therapy Regulatory Boards. (2016). Teletherapy guidelines. AMFTRB.org. Retrieved September 30, 2021, from https://amftrb.org/wp-content/uploads/2017/ 05/Proposed-Teletherapy-Guidelines-DRAFT-as-of-09.12.16.pdf

Axline, V. M. (1950). Play therapy experiences as described by child participants. Journal of Consulting Psychology, 14(1), 53. https:// doi.org/10.1037/h0056179

Bailey, C. E. (2005). Children in therapy: Using the family as a resource. Norton.

Botkin, D. R. (2000). Family play therapy: A creative approach to including young children in family therapy. Journal of Systemic Therapies, 19(3), 31-42. https://doi.org/10.1521/jsyt.2000.19.3.31

Boydell, K. M., Hodgins, M., Pignatiello, A., Teshima, J., Edwards, H., \& Willis, D. (2014). Using technology to deliver mental health services to children and youth: A scoping review. Journal of Canadian Academy of Child and Adolescent Psychiatry, 23(2), 87-99.

Bromfield, R. (1994). The use of puppets in play therapy. Child and Adolescent Social Work Journal, 12(6), 435-444. https://doi.org/ 10.1007/BF01875812

Caldwell, B. E., Bischoff, R. J., Derrig-Palumbo, K. A., \& Liebert, J. D. (2017). Best practices in the online practice of couple and family therapy. Retrieved September 30, 2021, from https://www.aamft. org/Documents/Products/AAMFT_Best_Practices_for_Online_ MFT.pdf 
Campos, B. (2009). Telepsychology \& telehealth: Counselling conducted in a technology environment. Counselling, Psychotherapy, and Health, 5(1), 26-59.

Cravens, J. (2020). Adaptations of therapists' theory of therapy: Preparing for teletherapy services. Family Therapy Magazine.

Desmond, K., Kindsvatter, A., Stahl, S., \& Smith, H. (2015). Using creative techniques with children who have experienced trauma. Journal of Creativity in Mental Health, 10(4), 439-455. https:// doi.org/10.1080/15401383.2015.1040938

Dimitropoulos, A., Zyga, O., \& Russ, S. (2017). Evaluating the feasibility of a play-based telehealth intervention program for children with Prader-Willi syndrome. Journal of Autism and Developmental Disorders, 47(9), 2814-2825. https://doi.org/10.1007/ s10803-017-3196-z

Drewes, A. A., Bratton, S. C., \& Schaefer, C. E. (2011). Integrative play. Wiley.

Eaker, B. (1986). Unlocking the family secret in family play therapy. Child Adolescent Social Work Journal, 3, 235-253. https://doi. org/10.1007/BF00758255

Fleming, A. P., McMahon, R. J., \& King, K. M. (2017). Structured parent-child observations predict development of conduct problems: The importance of parental negative attention in child-directed play. Prevention Science, 18, 257-267. https://doi.org/10.1007/ s11121-016-0672-1

Fromberg, D. P., \& Bergen, D. (1988). Play from birth to twelve and beyond: Contexts, perspectives, and meanings (2nd ed.). Garland Pub.

Grady, B., Myers, K. M., Nelson, E. L., Belz, N., Bennett, L., Carnahan, L., Decker, V. B., Holden, D., Perry, G., Rosenthal, L., Rowe, N., Spaulding, R., Turvey, C. L., White, R., \& Voyles, D. (2011). Evidence-based practice for telemental health. Telemedicine and E-Health, 17(2), 131-148. https://doi.org/10.1089/tmj.2010.0158

Haley, J., \& Richeport-Haley, M. (2003). The art of strategic therapy. Brunner-Routledge.

Harter, S. (1977). A cognitive-developmental approach to children's expression of conflicting feelings and a technique to facilitate such expression in play therapy. Journal of Consulting and Clinical Psychology, 45(3), 417-432. https://doi.org/10.1037/0022-006X. 45.3.417

Kaminski, J. W., \& Claussen, A. H. (2017). Evidence base update for psychosocial treatments for disruptive behaviors in children. Journal of Clinical Child \& Adolescent Psychology, 46(4), 477-499. https://doi.org/10.1080/15374416.2017.1310044

Kaminski, J. W., Valle, L. A., Filene, J. H., \& Boyle, C. L. (2008). A meta-analytic review of components associated with parent training program effectiveness. Journal of Abnormal Child Psychology, 36(4), 567-589. https://doi.org/10.1007/s10802-007-9201-9

Landreth, G. (2002). Therapeutic limit setting in the play therapy relationship. Professional Psychology: Research and Practice, 33(6), $529-535$.

Landreth, G. (2012). Play therapy: The art of relationship (3rd ed.). Routledge.

Lin, Y. C. (2010). Improving parent-child relationships through block play. Education, 130(3), 461-471.

Lin, Y. W., \& Bratton, S. C. (2015). A meta-analytic review of childcentered play therapy approaches. Journal of Counseling and Development, 93(1), 45-58. https://doi.org/10.1002/j.1556-6676. 2015.00180.x

Lingley-Pottie, P., \& McGrath, P. J. (2008). Telehealth: A child and family-friendly approach to mental health-care reform. Journal of Telemedicine and Telecare, 14(5), 225-226. https://doi.org/10. 1258/jtt.2008.008001

Luxton, D. D., Nelson, E. L., \& Maheu, M. M. (2016). A practitioner's guide to telemental health: How to conduct legal, ethical, and evidence-based telepractice. American Psychological Association. https://doi.org/10.1037/14938-000

Myers, K., Vander Stoep, A., Zhou, C., McCarty, C. A., \& Katon, W. (2015). Effectiveness of a telehealth service delivery model for treating attention-deficit/hyperactivity disorder: A communitybased randomized controlled trial. Journal of the American Academy of Child \& Adolescent Psychiatry, 54(4), 263-274. https:// doi.org/10.1016/j.jaac.2015.01.009

National Network to End Domestic Violence (2021). Technology Safety. Retrieved September 30, 2021, from https://www.techs afety.org/

Nelson, E. L., \& Patton, S. (2016). Using videoconferencing to deliver individual therapy and pediatric psychology interventions with children and adolescents. Journal of Child and Adolescent Psychopharmacology, 26(3), 212-221. https://doi.org/10.1089/cap. 2015.0021

New South Wales Government (2021). Violence, abuse, and neglect in telehealth. Retrieved September 30, 2021, fromhttps://www. health.nsw.gov.au/Infectious/covid-19/Pages/van-telehealth.aspx

O'Connor, K. J. (2001). Ecosystemic play therapy. International Journal of Play Therapy, 10(2), 33-44. https://doi.org/10.1037/h0089 478

Peckett, H., MacCallum, F., \& Knibbs, J. (2016). Maternal experience of Lego therapy in families with children with autism spectrum conditions: What is the impact on family relationships? Autism, 20(7), 879-887. https://doi.org/10.1177/1362361315621054

Perle, J. G., Langsam, L. C., Randel, A., Lutchman, S., Levine, A. B., Odland, A. P., Nierenberg, B., \& Marker, C. D. (2013). Attitudes toward psychological telehealth: Current and future clinical psychologists' opinions of Internet-based interventions. Journal of Clinical Psychology, 69(1), 100-113. https://doi.org/10.1002/ jclp. 21912

Perle, J. G., \& Nierenberg, B. (2013). How psychological telehealth can alleviate society's mental health burden: A literature review. Journal of Technology in Human Services, 31(1), 22-41. https:// doi.org/10.1080/15228835.2012.760332

Piaget, J. (1962). The stages of the intellectual development of the child. Bulletin of the Menninger Clinic, 26(3), 120.

Rasmussen, L. A., \& Cunningham, C. (1995). Focused play therapy and non-directive play therapy: Can they be integrated? Journal of Child Sexual Abuse, 4(1), 1.

Strehle, E. M., \& Shabde, N. (2006). One hundred years of telemedicine: Does this new technology have a place in paediatrics? Archives of Disease in Childhood, 91(12), 956-959. https://doi. org/10.1136/adc.2006.099622

Tate, K. A., Lopez, C., Fox, R., Love, J. R., \& McKinney, E. (2014). Inhome counseling for young children living in poverty: An exploration of counseling competencies. The Family Journal, 22(4), 371-381. https://doi.org/10.1177/1066480714530268

VanFleet, R., Sywulak, A. E., \& Sniscak, C. C. (2010). Child centered play therapy. Guilford.

Wade, S. L., Wolfe, C. R., \& Pestian, J. P. (2004). A web-based family problem-solving intervention for families of children with traumatic brain injury. Behavior Research Methods, Instruments, \& Computers, 36, 261-269. https://doi.org/10.3758/BF03195572

Wrape, E., \& McGinn, M. (2019). Clinical and ethical considerations for delivering couple and family therapy via telehealth. Journal of Marital and Family Therapy, 45(2), 296-308. https://doi.org/ 10.1111/jmft.12319

Publisher's Note Springer Nature remains neutral with regard to jurisdictional claims in published maps and institutional affiliations. 